\title{
Comparison of ethinylestradiol and nonylphenol effects on reproduction of Chinese rare minnows (Gobiocypris rarus) ${ }^{i 2}$
}

\author{
Jinmiao Zha ${ }^{\mathrm{a}}$, Liwei Sun ${ }^{\mathrm{a}}$, Philip A. Spear ${ }^{\mathrm{b}}$, Zijian Wang ${ }^{\mathrm{a}, *}$ \\ ${ }^{\mathrm{a}}$ State Key Laboratory of Environmental Aquatic Chemistry, Research Center for Eco-Environmental Sciences, Chinese Academy of Sciences, \\ P.O. Box 2871, Beijing 100085, PR China \\ ${ }^{\mathrm{b}}$ Centre de Recherche TOXEN, Département des Sciences Biologiques, Université du Québec à Montréal, C.P. 8888 , \\ Succursale Centre-Ville, Montréal, Quebec, Canada H3C 3 P8
}

Received 13 September 2007; received in revised form 28 November 2007; accepted 30 November 2007

Available online 21 February 2008

\begin{abstract}
Breeding pairs of rare minnows were exposed to $5,10,20 \mu \mathrm{g} / \mathrm{L}$ 4-nonylphenol (NP) or $4 \mathrm{ng} / \mathrm{L} 17 \alpha$-ethinylestradiol (EE $_{2}$ ) for 21 days. Among reproductive parameters investigated, fecundity, fertility, and laying interval were significantly affected by $4 \mathrm{ng} / \mathrm{L} \mathrm{EE}_{2}$, but were not affected at any exposure level of NP. These effects coincided with male feminization, ova-testis, increased plasma VTG in both males and females as well as the accumulation of eosinophilic material in kidneys and livers. Histopathologic evaluation revealed severe kidney lesions in both $\mathrm{EE}_{2}$ and NP-exposed fish. The bioassay succeeded in demonstrating that $\mathrm{EE}_{2}$ was several orders of magnitude more potent than the industrial chemical NP. The rare minnow was more sensitive to $\mathrm{EE}_{2}$ than medaka, but comparable to zebrafish in terms of sensitivity. The results of the present investigation indicated that a short-term reproductive bioassay is feasible using the Chinese rare minnow as the test species.
\end{abstract}

(C) 2007 Elsevier Inc. All rights reserved.

Keywords: Gobiocypris rarus; Vitellogenin; Histopathology; Reproduction; 17 $\alpha$-Ethinylestradiol; 4-Nonylphenol

\section{Introduction}

Adverse effects of xenobiotic chemicals capable of disrupting the endocrine systems of wildlife species are of increasing concern (Nichols et al., 1999; Solé et al., 2003; Liney et al., 2005). The capacity to mimic natural steroids is found in diverse chemical groups including organochlorine pesticides, polychlorinated biphenyls, dioxins, alkylphenols, phthalates (Jobling et al., 1996; Groonen et al., 1999) as well as natural and synthetic steroids (Ternes et al., 1999; Liney et al., 2005).

Prominent among the alkylphenols, 4-nonylphenol (NP) enters the aquatic environment as a degradation product of nonylphenol ethoxylates (NPEO) used as nonionic surfac-

\footnotetext{
Any studies in this paper involving rare minnow (Gobiocypris rarus) were conducted in accordance with national and institutional guidelines for the protection of human subjects and animal welfare.

${ }^{*}$ Corresponding author. Fax: + 861062929140 .

E-mail address: wangzj@rcees.ac.cn (Z. Wang).
}

tants in a variety of industrial and agricultural processes and as cleaning agents (Tolls et al., 1994). Field surveys have revealed that nonylphenols are distributed at low $\mu \mathrm{g} / \mathrm{L}$ levels in the aquatic environment (Tsuda et al., 2001). More specifically, the US Geological Survey reported that $\mathrm{NP}$ was one of the most frequently detected compounds with a median concentration of $0.8 \mu \mathrm{g} / \mathrm{L}$ (Kolpin et al., 2002). Nonylphenols have been found to range from $<0.2$ to $12 \mu \mathrm{g} / \mathrm{L}$ in polluted British river waters (Blackburn and Waldock, 1995) and $<0.3$ to $45 \mu \mathrm{g} / \mathrm{L}$ in the Swiss river waters (Ahel et al., 1994). Several studies have demonstrated that NP affects teleost reproduction. Noteably, NP induces the female-specific, egg-yolk precursor vitellogenin (VTG) in males (Jobling et al., 1996; Ishibashi et al., 2006), causes testis-ova (Gray and Metcalfe, 1997), and decreases fecundity and fertility (Ishibashi et al., 2006).

$17 \alpha$-ethinylestradiol $\left(\mathrm{EE}_{2}\right)$, a synthetic estrogen, has an extensive distribution in the aquatic environment. Median concentrations of $\mathrm{EE}_{2}$ ranged from 1 to $17 \mathrm{ng} / \mathrm{L}$ in sewage treatment effluents and ranged from below the detection 
limit to $15 \mathrm{ng} / \mathrm{L}$ in surface waters (Ternes et al., 1999; Komori et al., 2004; Liney et al., 2005). $\mathrm{EE}_{2}$ has been shown to affect elements of the steroid hormone signaling pathway in vitro (Thorpe et al., 2003; Van den Belt et al., 2004) and disrupt endocrine systems in vivo (Van den Belt et al., 2002; Nash et al., 2004; Palace et al., 2006). Among $\mathrm{EE}_{2}$ effects in fish are VTG induction in males (Seki et al., 2002), the reduction of yolk-filled oocytes in females (Van den Belt et al., 2001), and organ toxicity (Hahlbeck et al., 2004) in addition to decrease fecundity and fertility (Nash et al., 2004).

The present investigation was designed to compare the reproductive effects of two representative endocrinedisrupting chemicals (EDCs), NP and $\mathrm{EE}_{2}$, at environmentally relevant exposure concentrations. The study also attempts to investigate possible mechanistic links to organ toxicity at low exposures through histopathologic evaluation. A third objective is to examine the suitability of a short-term reproductive bioassay using the Chinese rare minnow in the context of low-level exposure to endocrine modulators.

Short-term reproduction bioassays have been developed for several species including fathead minnow (Pimephales promelas) and medaka (Oryzias latipes) (Harries et al., 2000; Ankley et al., 2001; Seki et al., 2002) and are considered pertinent to the evaluation of effects of EDCs. The Chinese rare minnow belongs to the family Cyprinidae and its natural distribution is limited to the upstream waters of the Yangtze River, Sichuan Province, China. Rare minnow are small (30-80 $\mathrm{mm}$ in total length) and easy to culture in the laboratory. They have a relatively short life cycle, spawning hundreds of eggs with high fertilization and hatching rates. Males and females are easily distinguished in adults according to secondary sexual characteristics (Wang, 1992). Rare minnows have been used previously for aquatic toxicity testing (Zhou et al., 1995) and our previous work has reported short-term toxic effects, such as histological alterations in rare minnow exposed to $\mathrm{EE}_{2}$ and NP (Zha et al., 2007).

\section{Material and methods}

\subsection{Chemicals}

Reagent $17 \alpha$-ethinylestradiol $\left(\mathrm{EE}_{2}\right)(98 \%$ purity) was obtained from Sigma (St. Louis, MO, USA). Technical 4-nonylphenol (NP) (SigmaAldrich, Deisenhofen, Germany) consisted of $98 \%$ NP isomers $(90 \%$ $4-\mathrm{NP}, 10 \% 2-\mathrm{NP}$ ) and $2 \%$ dinonylphenol. To prepare stock solutions, $\mathrm{EE}_{2}$ and NP were diluted in HPLC-grade acetone and then mixed with distilled-deionized water. Final exposure concentrations were achieved by means of a dilution apparatus constructed of polytetrafluorethylene (PFTE) and isoversinic tubes (Abimed, Langenfeld, Germany). The final acetone concentration was less than $0.01 \%$.

\subsection{Fish}

Rare minnows were provided by the Institute of Hydrobiology, the Chinese Academy of Sciences. The brood stock was kept in flow-through systems supplied with charcoal-filtered, dechlorinated tap water at
$25 \pm 2{ }^{\circ} \mathrm{C}$ at a photoperiod of $16: 8 \mathrm{~h}$ (light:dark). Fish were generally fed with a commercial granular food (Trea, Germany) at a rate of $0.1 \%$ body weight per day and dry brine shrimp (Artemia).

\subsection{Exposure and experimental set-up}

Sexually mature rare minnow (about 9-months old) were the offspring of the same pair of brood stock. The body weights and lengths were $2.3 \pm 0.5 \mathrm{~g}$ and $48.3 \pm 5.6 \mathrm{~mm}$, respectively. Each reproductive tank $(18 \mathrm{~L})$ contained one female and one male adult rare minnow. Paired fish were monitored for 2 weeks prior to the initiation of chemical exposure and, based on these data, eight breeding pairs of rare minnow per treatment ( $\times 6$ treatments), total of 48 breeding pairs were selected. Breeding pairs were continuously exposed to $5,10,20 \mu \mathrm{g} / \mathrm{L} \mathrm{NP}$ or $4 \mathrm{ng} / \mathrm{L} \mathrm{EE}_{2}$ under flowthrough conditions for 21 days. Solvent control aquaria received $0.1 \%$ acetone and water control tanks were supplied with dechlorinated tap water. Each toxicant concentration and control had eight replicates. The flow rate was $10 \mathrm{~L} / \mathrm{h}$

Paired fish were examined daily to assess survival, reproductive behavior and spawning activity. All eggs were removed from the test tanks after paired fish laid eggs, counted and examined microscopically to determine fertility. Embryos ( $n=150$ when possible) were selected from each spawn and separated into three groups with 50 embryos and maintained in their respective experimental solution to determine hatching success. Newly hatched fries $(n=50$ when possible) were selected from a subset of randomly chosen spawns and translated into two test chambers and maintained in their respective experimental solution to determine offspring growth and cumulative death rates. The experiment was terminated when the offspring were 15 days post-hatching. The offspring were anesthetized in $200 \mathrm{~mL}$ of dechlorinated tap water containing $200 \mathrm{mg} / \mathrm{L}$ MS-222 (3-aminobenzoic acid ethyl ester methane sulfonate salt; Sigma, St. Louis, MO, USA, A-5040), then body lengths and wet body weights were determined.

\subsection{Water concentrations of $E E_{2}$ and $N P$}

Water samples of $\mathrm{EE}_{2}$ and NP were collected every week and analyzed by gas chromatography 6890/mass spectrometry 5973 (Agilent, USA) and methods previously described in Zhou et al. $(2005,2007)$. Briefly, filtered water samples of $\mathrm{EE}_{2}$ were spiked with a deuterated surrogate standard, acidified, and concentrated on an SPE cartridge. $\mathrm{EE}_{2}$ was eluted in methanol/tert-butyl methyl ether $(1 / 9 ; \mathrm{v} / \mathrm{v})$ and derivatized BSTFA $+1 \%$ TMCS $+5 \%$ TMSI. Recovery of $\mathrm{EE}_{2}$ from fortified water standards ranged from $97 \%$ to $120 \%$. Four liter of water sample was concentrated to final volume of $0.4 \mathrm{~mL}$. Detection limit for $\mathrm{EE}_{2}$ was $0.03 \mathrm{ng} / \mathrm{L}$. Filtered water samples of NP were acidified and concentrated on an SPE cartridge. NP was eluted in methanol/dichloromethane $(1 / 9 ; \mathrm{v} / \mathrm{v})$ and derivative BSTFA $+1 \%$ TMCS. Recovery of NP from fortified water standards ranged from $95 \%$ to $112 \%$. One liter of water sample was concentrated to final volume of $1 \mathrm{~mL}$. Detection limit for NP was $10 \mathrm{ng} / \mathrm{L}$. The analyzed concentrations (mean \pm S.D.; and $\%$ analyzed/nominal) of $\mathrm{EE}_{2}$ in the test solutions during the exposure period were $3.61 \pm 0.53(90 \%) \mathrm{ng} / \mathrm{L}$. In addition, the analyzed concentrations of NP were $4.52 \pm 0.83(90 \%)$, $9.13 \pm 1.03(91 \%)$, and $18.53 \pm 2.33(93 \%) \mu \mathrm{g} / \mathrm{L}$, respectively. Nominal $\mathrm{EE}_{2}$ and NP values are used in the following text.

\subsection{Measurement of plasma VTG}

Plasma VTG level was measured using the carp ELISA kit (Bioscience, German). To avoid confounding results with sampling time, individual fish were captured sequentially from each treatment group. The adult rare minnow were anesthetized. The root of the caudal fin of each adult fish was cut to collect blood with a heparinized microcapillary tube and $50 \mu \mathrm{L}$ was transferred to the sampling buffer supplied with the ELISA kit. Then the diluted blood specimen was immediately centrifuged $(8000 \times g, 10 \mathrm{~min}$, $4{ }^{\circ} \mathrm{C}$ ) and frozen at $-80^{\circ} \mathrm{C}$ until use. 


\subsection{Gonadosomatic, hepatosomatic, and renal somatic indices}

Gonads, livers, and kidneys of adults were removed and weighed after the blood was collected. Gonadosomatic index (GSI), hepatosomatic index (HSI), and renal somatic index (RSI) were calculated as following: GSI $=$ gonad weights $(\mathrm{mg}) /$ body weights $(\mathrm{mg}) \times 100 ; \mathrm{HSI}=$ liver weights $(\mathrm{mg}) /$ body weights $(\mathrm{mg}) \times 100$; RSI $=$ kidney weights $(\mathrm{mg}) /$ body weights $(\mathrm{mg}) \times 100$.

\subsection{Reproductive endpoints determined}

Numbers of spawned eggs, fertilized eggs, and fries were determined. Laying interval (interval which same pair rare minnow continuously laid twice eggs) and time to hatch of embryos were recorded.

\subsection{Histological analysis}

After complete necropsy of all adult fish per treatment, gonads, livers, and kidneys were removed, fixed in buffered formalin (4\%), dehydrated and processed for paraffin wax embedding. The sections were cut at 3-4 $\mu \mathrm{m}$ and stained with hematoxylin and eosin (H\&E). The sections of the paraffin blocks were evaluated microscopically. Histological characteristic were described in our pervious studies (Zha et al., 2007). Numbers of adult fish with lesion tissues by histology were counted at the end of the 21 days reproductive exposure.

\subsection{Statistics}

All statistical analyses were performed by using Statistica (version 99) (SattSoft. Inc., USA). The experimental data except for the data on number of adult fish with lesion tissues by histology were checked for homogeneity of variance across treatments by using Levene's test. When the assumptions were met, the data were subjected to one-way analysis of variance followed by Dunnett's multiple comparison tests. When data were considered to be nonhomogeneous, the nonparametric KruskalWallis test was used followed by the Mann-Whitney $U$-test with Bonferroni's adjustment. The data on number of adult fish with lesion tissues by histology were assessed by Chi-square analysis. Statistical significance was set at $p \leqslant 0.05$.

\section{Results}

\subsection{Mortality, growth, and somatic indices}

During the experiment period, no adult fish died and growth in the toxicant-exposed groups was not different to that of controls (data not shown). Adult GSIs were significantly different between controls and males exposed to $10 \mu \mathrm{g} / \mathrm{L}$ NP (Fig. 1). Significantly increased HSI in females occurred only at $4 \mathrm{ng} / \mathrm{L} \mathrm{EE}_{2}$ (Fig. 1). The RSI in males was increased significantly at all exposures and in females was increased in the 10 and $20 \mu \mathrm{g} / \mathrm{L} \mathrm{NP}$ and $\mathrm{EE}_{2}$ groups (Fig. 1).

\subsection{Plasma vitellogenin (VTG) concentrations}

After 21 days of exposure to NP or $\mathrm{EE}_{2}$, plasma VTG concentrations of males ranged from $130 \mathrm{ng} / \mathrm{mL}$ in the controls to $600,000 \mathrm{ng} / \mathrm{mL}$ in the $\mathrm{EE}_{2}$ exposure group, while plasma VTG concentrations of females ranged from $300,000 \mathrm{ng} / \mathrm{mL}$ in the controls to $640,000 \mathrm{ng} / \mathrm{mL}$ in the $\mathrm{EE}_{2}$ group (Fig. 2). Male plasma VTG concentrations were significantly increased at all toxicant exposures. The plasma VTG concentrations of females increased significantly only in the $\mathrm{EE}_{2}$ exposure group (Fig. 2).

\subsection{Histopathology}

\subsubsection{Gonads}

In control minnows, seminiferous tubules of the testes were filled with large numbers of fertile sperm (Fig. 3A). Males exposed to $\mathrm{EE}_{2}$ and NP manifested the testis-ova phenomenon (Fig. 3C and D). Numbers of adult fish with ova-testis at $\mathrm{NP}$ and $\mathrm{EE}_{2}$ exposure groups at the end of 21 days reproductive exposure were $0,1,3$, and 6 , respectively (Table 1). Those at $20 \mu \mathrm{g} / \mathrm{L} \mathrm{NP}$ and $\mathrm{EE}_{2}$ exposure groups were significantly more than that of control $(p<0.05$ and $p<0.01$, respectively) (Table 1 ). After 21 days exposure to $\mathrm{NP}$ or $\mathrm{EE}_{2}$, the histological changes of ovaries from exposure groups were not significantly different from that of controls (Fig. 3B). Histological inspection of the ovaries revealed all stages of oocyte development including primary, secondary, and tertiary follicles at all exposure groups (Fig. 3B). In addition, ooctyes were detected in testes in the 10 and $20 \mu \mathrm{g} / \mathrm{L} \mathrm{NP}$ and $\mathrm{EE}_{2}$ exposure groups (Fig. 3C and D).

\subsubsection{Hepatic and renal tissue}

Abundant cytoplasmic lipid was observed in hepatocytes of control males (Fig. 4A). After 21 days exposure, hepatic tissue of the $\mathrm{EE}_{2}$ group was disorganized and hepatocytes were hypertrophic with enlargement of nuclei (Fig. 4B). In addition, considerable eosinophilic material was observed to have accumulated in the hepatic tissue of males (Fig. 4C). At the end of 21 days reproductive exposure, numbers of adult fish with lesion liver at $\mathrm{NP}$ and $\mathrm{EE}_{2}$ treatments were $1,4,7$, and 10 , respectively (Table 1 ). Those at the 10 and $20 \mu \mathrm{g} / \mathrm{L} \mathrm{NP}$ and $\mathrm{EE}_{2}$ treatments were significantly more than those of controls $(p<0.05, p<0.01$, and $p<0.01$, respectively) (Table 1 ). However, no lesion livers of adult fish in the controls were observed (Table 1).

Normal renal tissues were composed of numerous renal corpuscles with well-developed glomeruli and an intricate system of tubules (Fig. 4D). The segment was lined with large, clear columnar epithelial cells having central nuclei and the brush border was reduced or nonexistent (Fig. 4D). After exposure to $20 \mu \mathrm{g} / \mathrm{L} \mathrm{NP}$ or $\mathrm{EE}_{2}$, lesions of renal tissue were characterized by severe hemorrhaging within the kidney tubules, the Bowman s space and the renal interstitium (Fig. 4E). In addition, we observed eosinophilic material accumulated in the sinusoids of the head kidney of male fish (Fig. 4F). At the end of 21 days reproductive exposure, numbers of adult fish with lesion kidney at $\mathrm{NP}$ and $\mathrm{EE}_{2}$ treatments were 3, 6, 10, and 12 , respectively (Table 1$)$. Those at treatments were significantly more than those of controls $(p<0.05, p<0.01$, $p<0.01$, and $p<0.01$, respectively) (Table 1). However, no lesion kidneys of adult fish in the controls were observed (Table 1). 

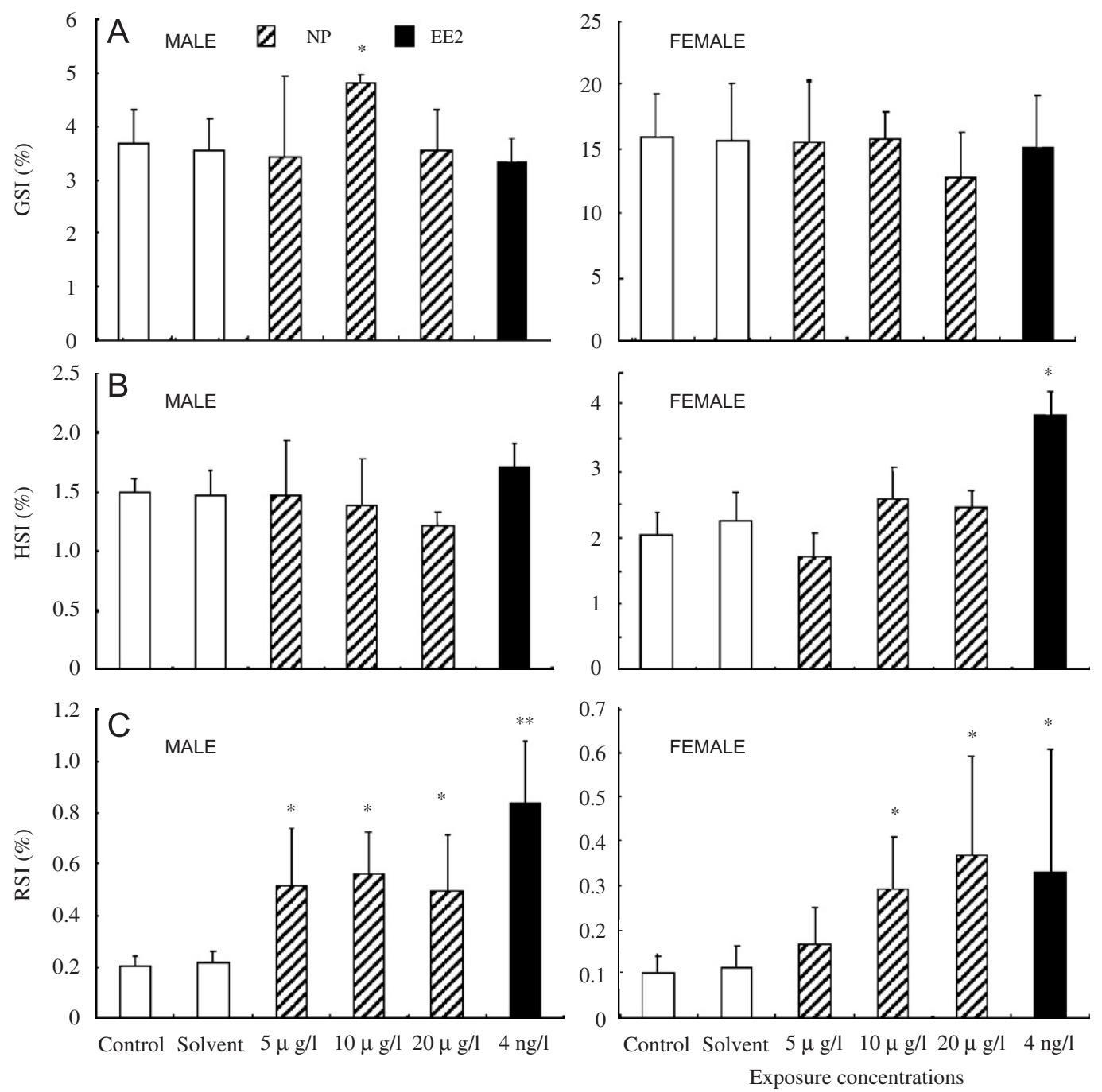

Fig. 1. Gonadosomatic index (A), hepatosomatic index (B), and renal somatic index (C), in breeding rare minnow at the end of the 21 days reproductive exposure. Each value is the mean \pm S.E.M. of eight fish. Asterisk $\left(^{*}\right)$ indicates significant difference from the control group $(p<0.05)$.

\subsection{Reproduction}

\subsubsection{Fecundity and fertility}

Fig. 5 illustrates that the mean laying interval at 5,10 , and $20 \mu \mathrm{g} / \mathrm{L} \mathrm{NP}$ and $4 \mathrm{ng} / \mathrm{L} \mathrm{EE}_{2}$ exposure concentrations were $3.5 \pm 0.7,3.4 \pm 0.7,3.7 \pm 1.2$, and $11.5 \pm 0.7$ days. There was a significant decrease in the spawning frequency in the $\mathrm{EE}_{2}$ group as compared with controls $(3.4 \pm 1.8$ days) $(p<0.05)$. The mean number of eggs laid per female and the mean number of eggs laid per batch in the $\mathrm{EE}_{2}$ group were significantly less than those of controls $(p<0.01)$ (Fig. 6). None of the eggs spawned by $E_{2}$-exposed minnow was fertilized and the effect was significantly different from controls $(p<0.001)$ (Fig. 7). With respect to the NP exposures, however, fecundity and fertility were not affected.

\subsubsection{Hatching, growth, and survival of larvae}

Hatching rates of embryos at NP treatments were not significantly different from those of controls (Table 2).
Body lengths and weights of NP-exposed larvae were not affected by the toxicant (Table 2). In addition, no significant statistical differences were observed in cumulative death rates of larvae (Table 2). These parameters could not be evaluated in the $\mathrm{EE}_{2}$-exposed group due to egg infertility.

\section{Discussion}

The 21 days low-level exposure of breeding rare minnows succeeded in demonstrating adverse effects of two representative EDCs. Large differences in toxic potency and qualitative differences in response to the EDCs were revealed. Not only standard reproductive parameters (e.g., fecundity, fertility, embryo development, survival, and growth of larvae), but also other types of toxic endpoints (e.g., target organ effects, VTG biomarker) were evaluated. It clarifies that short-term assay presented is suitable for screening for estrogenic chemicals. 


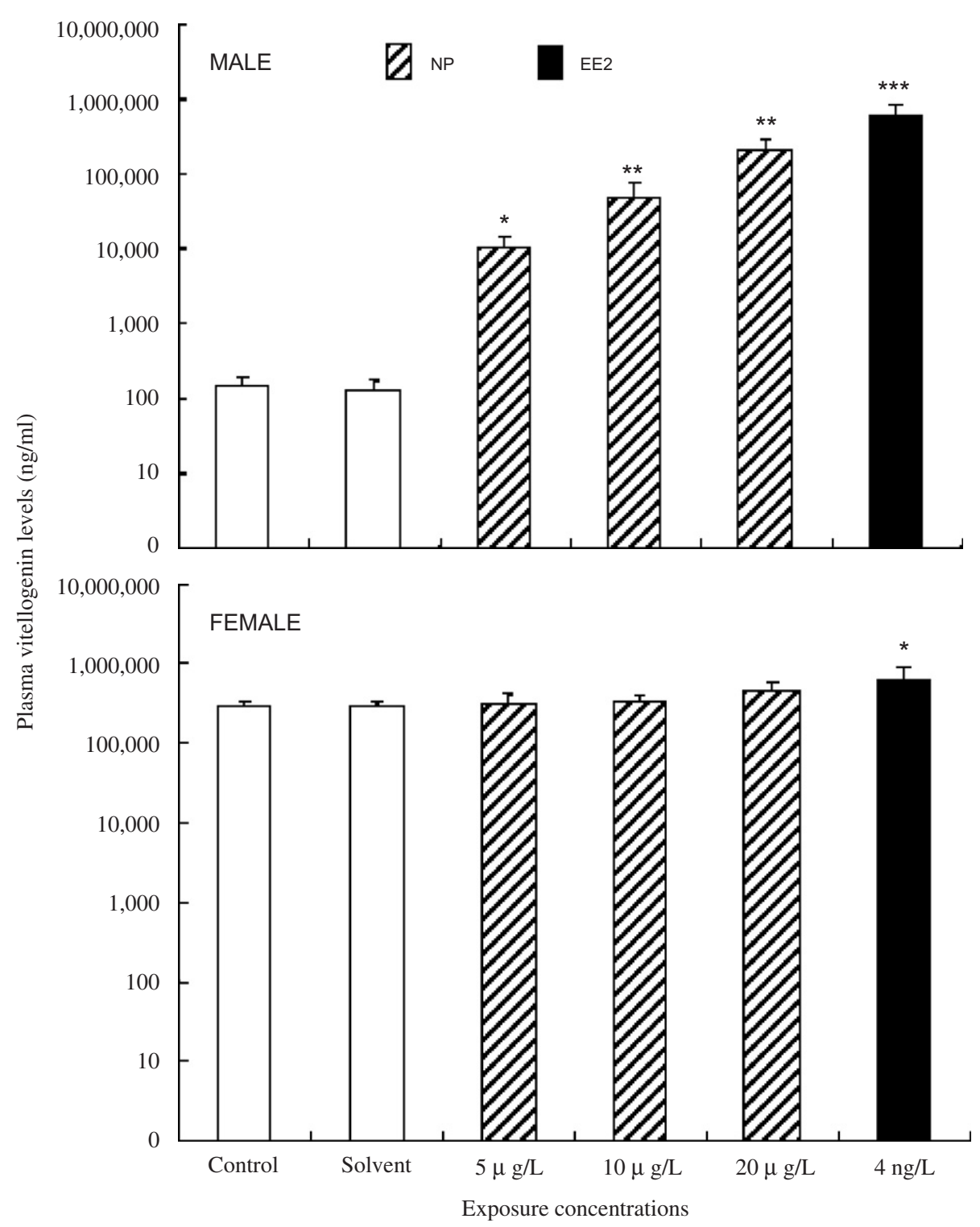

Fig. 2. Plasma vitellogenin concentrations of paired mature rare minnow at the end of the 21 days reproductive exposure. Asterisks $(*),(* *)$, and $(* * *)$ indicate significant differences from the control $(p<0.05, p<0.01$, and $p<0.001$, respectively).

\subsection{Reproduction, growth, and survival of larvae}

Growth of the breeding rare minnows was not affected by the EDCs which concur with previous results of NP-exposed medaka (Ishibashi et al., 2006). In a longterm exposure of zebrafish, $\mathrm{EE}_{2}$ concentrations of 0.1 and $1 \mathrm{ng} / \mathrm{L}$ did not affect growth, whereas higher concentrations of $\mathrm{EE}_{2}(10$ and $25 \mathrm{ng} / \mathrm{L})$ affected total body length and weight (Van den Belt et al., 2003). The lack of growth effects in adult rare minnows at $4 \mathrm{ng} / \mathrm{L} \mathrm{EE}_{2}$ in the present study is consistent with these results for zebrafish.

With respect to larvae, NP had no significant effects on rare minnow growth or survival (Table 1) and the same results have been reported for medaka exposed to a similar range of NP concentrations (i.e., 4.2, 8.2, and $17.7 \mu \mathrm{g} / \mathrm{L}$ ) (Yokota et al., 2001). Another study with medaka larvae reported that 10 and $50 \mu \mathrm{g} / \mathrm{L}$ NP did not affect growth or survival (Ishibashi et al., 2006) which is also consistent with the present study.

The fecundity and fertility were significantly affected by $4 \mathrm{ng} / \mathrm{L} \mathrm{EE}_{2}$ (Figs. 6 and 7). In a previous study, a significant reduction in fecundity and fertility was observed after 21 days exposure of medaka to $488 \mathrm{ng} / \mathrm{L} \mathrm{EE}$, while lower exposure concentrations $(32.6,63.9,116$, and $261 \mathrm{ng} / \mathrm{L}$ ) did not affect this reproductive parameter (Seki et al., 2002). In addition, Van den Belt et al. (2003) reported that the fecundity of zebrafish was not affected following exposure to 0.1 and $1 \mathrm{ng} / \mathrm{L} \mathrm{EE}$, whereas 10 and $25 \mathrm{ng} / \mathrm{L} \mathrm{EE} \mathrm{EE}_{2}$ decreased fecundity. Based on the limited set of results for fecundity, the rare minnow is apparently more sensitive to $\mathrm{EE}_{2}$ than medaka (i.e., 100-fold lower effective concentration), but comparable to zebrafish in terms of sensitivity.

The degree of sensitivity is crucial in developing bioassays for EDCs. In the case of $\mathrm{EE}_{2}$, for example, 

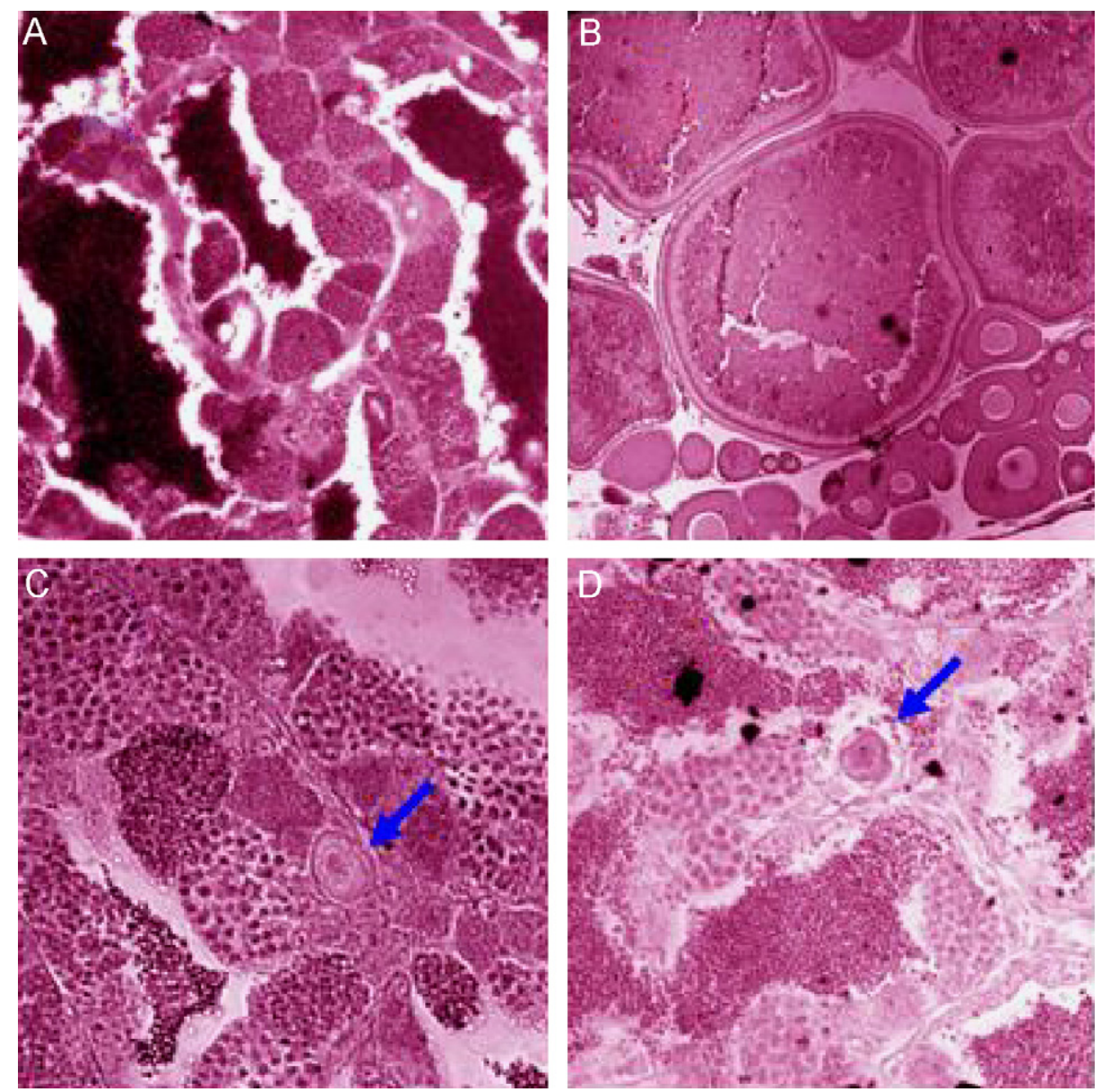

Fig. 3. Light micrographs of gonad tissue of adult rare minnow at the end of the reproductive assay, stained with H\&E: (A) normal mature testis from control ( $\times 400)$; (B) normal mature ovary from control ( $\times 100)$; (C) ova-testis from $4 \mathrm{ng} / \mathrm{L} \mathrm{EE}_{2}$ group, arrow showing perinucleolar occytes $(\times 400)$; (D) ova-testis from $20 \mu \mathrm{g} / \mathrm{L} \mathrm{NP}$ group, showing perinucleolar occytes $(\times 400)$.

Table 1

Number of adult rare minnow with lesion gonads, livers, and kidneys by histological investigations at the end of the 21 days reproductive exposure

Concentration Males Females No. of adult rare minnow

Testis-ova Lesion livers Lesion livers

\begin{tabular}{llllcc}
\hline Control & 8 & 8 & 0 & 0 & 0 \\
Solvent & 8 & 8 & 0 & 0 & 0 \\
$5 \mu \mathrm{g} / \mathrm{L}$ NP & 8 & 8 & 0 & 1 & $3^{* *}$ \\
$10 \mu \mathrm{g} / \mathrm{L} \mathrm{NP}$ & 8 & 8 & 1 & $4^{*}$ & $6^{* *}$ \\
$20 \mu \mathrm{g} / \mathrm{L} \mathrm{NP}$ & 8 & 8 & $3^{* *}$ & $7^{* *}$ & $10^{* *}$ \\
$4 \mathrm{ng} / \mathrm{L} \mathrm{EE}{ }_{2}$ & 8 & 8 & $6^{* *}$ & $10^{* *}$ & $12^{* *}$ \\
\hline
\end{tabular}

Asterisks $(*)$ and $(* *)$ showed significant differences from the values of solvent controls or controls at $p<0.05$ and $p<0.01$, respectively; the statistic methods was Chi-squared analysis.

median concentrations ranged from 1 to $17 \mathrm{ng} / \mathrm{L}$ in sewage treatment effluents and ranged from below the detection limit to $15 \mathrm{ng} / \mathrm{L}$ in surface waters (Ternes et al., 1999; Komori et al., 2004; Liney et al., 2005). Therefore, a shortterm rare minnow reproduction assay with fecundity and fertility as endpoints would be feasible to screen effluents and surface waters. The toxic response of the rare minnow (present study) and zebrafish (e.g., Van den Belt et al., 2003 ) would suggest that environmental $\mathrm{EE}_{2}$ posed a significant risk to the reproduction of freshwater fish.

Conversely, in the case of NP, the present experiment and published literature (e.g., Yokota et al., 2001; Kang et al., 2003; Ishibashi et al., 2006) demonstrate that concentrations $\leqslant 20 \mu \mathrm{g} / \mathrm{L}$ are below threshold for reproductive effects while reproductive LOAELs are in the $52-100 \mu \mathrm{g} / \mathrm{L}$ range for freshwater fish. Given that surface water NP concentrations are typically well below these toxic levels (see Section 1; Ahel et al., 1994; Blackburn and Waldock, 1995; Tsuda et al., 2001; Kolpin et al., 2002). However, NP is a degradation product of NPEOs and usually co-occurs with other often more potent alkylphenols (APs). Previously numerous studies have examined the effects of individual APs (usually OP or NP) on the reproductive health of fish. Recently, some studies that have investigated the potential estrogenic effects of the APs found in produced water and effects on reproduction system of Atlantic cod (Gadus morhua) (Thomas et al., 2004; Meier et al., 2007). These results suggested that relative low concentration NP combined with other APs 

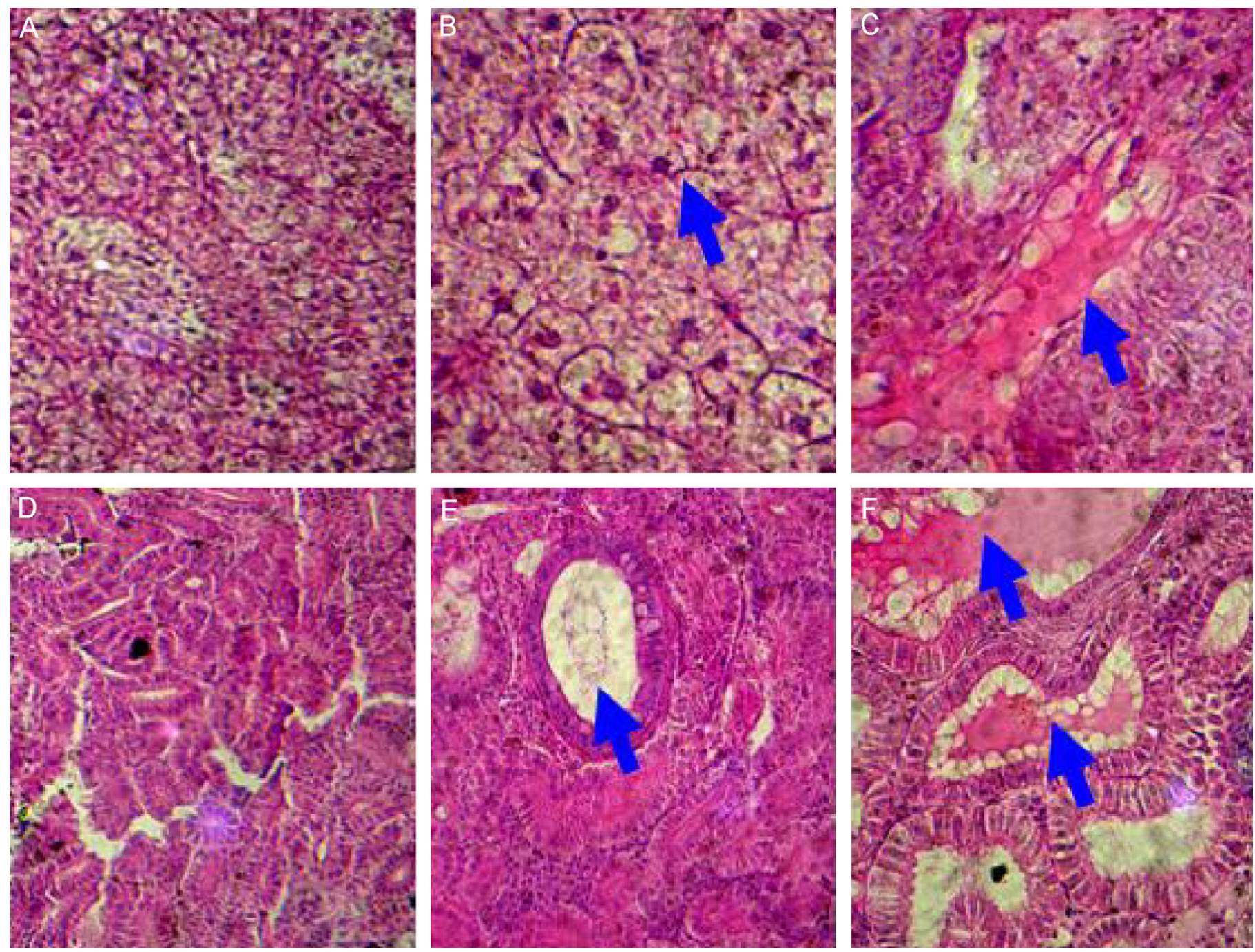

Fig. 4. Light micrographic investigation of hepatic and renal tissue of male adult rare minnow at the end of reproductive assay, stained with $\mathrm{H} \& \mathrm{E}(\times 400)$ : (A) normal hepatic tissue from control; (B) hepatic tissue from $4 \mathrm{ng} / \mathrm{L} \mathrm{EE}_{2}$ group, arrow shows enlargement of cell nuclei; (C) hepatic tissue from $4 \mathrm{ng} / \mathrm{L}$ $\mathrm{EE}_{2}$ group, arrow shows accumulated eosinophilic material; (D) renal tissue from control; (E) renal tissue from $20 \mu \mathrm{g} / \mathrm{L}$ NP group, arrow shows accumulated eosinophilic material; (F) renal tissue from $4 \mathrm{ng} / \mathrm{L} \mathrm{EE}_{2}$ group, arrow shows accumulated eosinophilic material.

would cause reproductive effects. In these studies, NP was an important ingredient of APs which caused reproductive effects. Therefore, NP, especially combined with other APs, could pose as great a risk to the reproduction of freshwater fish.

It is interesting to note that $\mathrm{EE}_{2}$ caused a significant decrease in spawning frequency (i.e., greater laying interval; Fig. 5) which may be ascribed to many possible endocrine-related mechanisms. Casual observations of the $\mathrm{EE}_{2}$-exposed male rare minnow revealed lesions of sexual behavior (including following, dancing, floating, and crossing) (data not shown), which may have contributed to the effect on the spawning interval. In previous studies, suppression of sexual behavior in female medaka exposed to endocrine disruptors including $17 \beta$-estradiol $\left(\mathrm{E}_{2}\right)$ and tributyltin were observed (Oshima et al., 2003; Nakayama et al., 2004). These results suggested that sexual behavior was a good indicator for evaluating fish reproduction.

\section{2. $V T G$}

The representative EDCs examined in the present study are "estrogenic" in that they are capable of binding to $E_{2}$ receptors, activating transcriptional process and inducing the synthesis of $E_{2}$ gene products such as VTG. Under normal conditions, male fish poses the basic components of the $\mathrm{E}_{2}$ signaling pathway and lack only a receptor ligand. Thus, VTG mRNA expression and VTG concentrations in males are markers for EDCs that act as receptor ligands. In this study, the highest plasma VTG concentration occurred in $\mathrm{EE}_{2}$-exposed rare minnow (Fig. 2) and coincided with significant effects on reproductive endpoints (i.e., increased spawning interval, decreased fecundity, and decreased fertility; Figs. 5-7). Similarly, VTG induction has been associated with effects on fertilization in medaka exposed to octylphenol (Groonen et al., 1999). However, VTG induction is not always a hallmark of EDCs' reproductive 


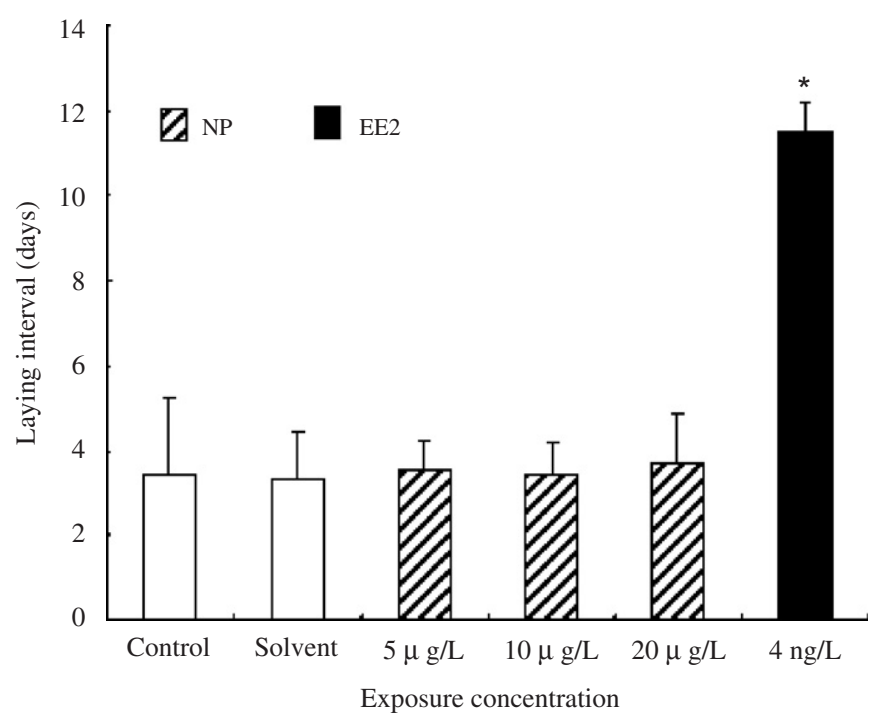

Fig. 5. Laying interval of paired mature rare minnow during the 21 days reproductive assay. Asterisk $(*)$ indicates significant difference from the control group $(p<0.05)$.
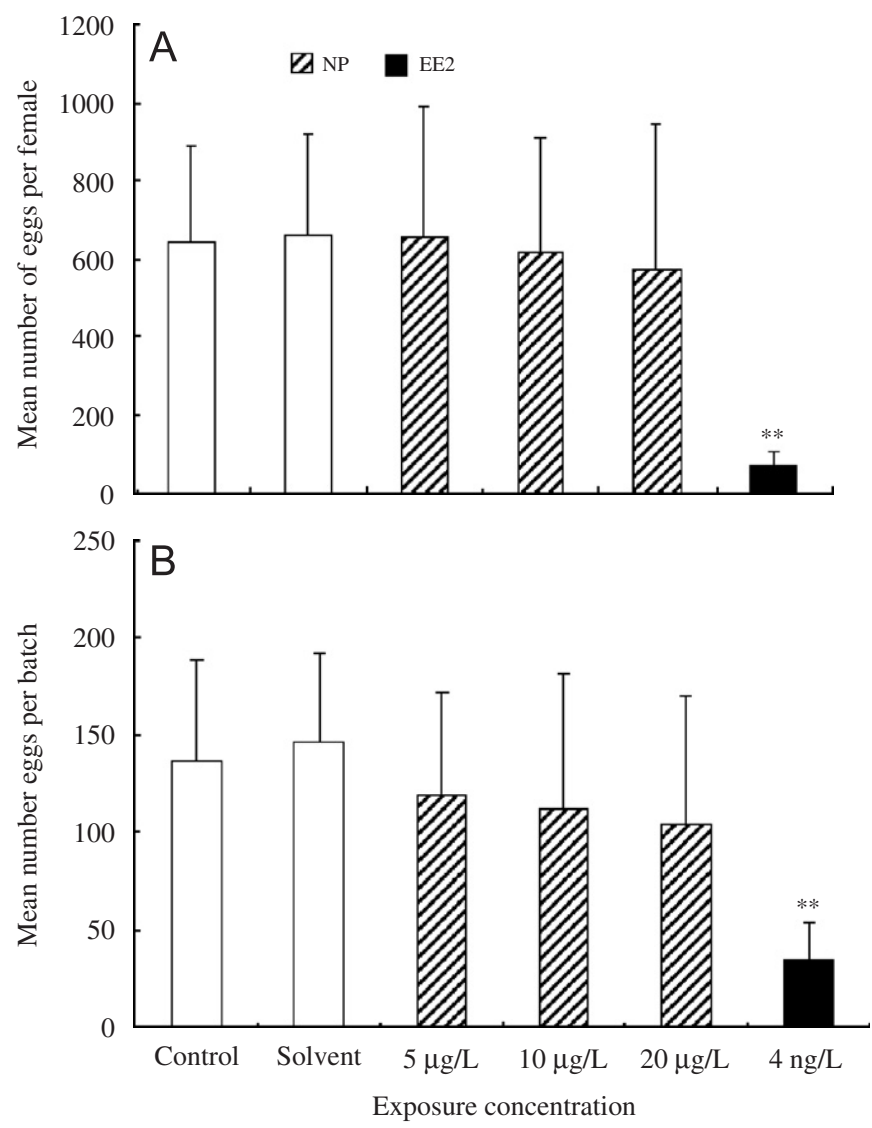

Fig. 6. Mean number of eggs per female (A) and mean number of eggs per batch (B) of breeding rare minnows during the 21 days reproductive assay. Asterisks $(*)$ and $(* *)$ indicate significantly differences from the control group $(p<0.05$ and $p<0.01$, respectively).

effects. For example, plasma VTG in $\mathrm{E}_{2}$-exposed, male fathead minnow was less sensitive than diminished egg production when $\mathrm{EC}_{50} \mathrm{~s}$ were compared, although the two endpoints were significantly correlated (Kramer et al., 1998).

In addition to VTG, several other $\mathrm{EE}_{2}$ effects were consistent with stimulation of the $\mathrm{E}_{2}$ signaling pathway. Seki et al. (2002) showed that increased VTG in medaka were eight-fold more sensitive to $\mathrm{EE}_{2}$ compared with concentrations affecting reproduction. In addition, Lange et al. (2001) showed that significantly increased VTG in fathead minnow exposed to $\mathrm{EE}_{2}$ were relative to reproductive effects.

All concentrations of NP increased plasma VTG in male rare minnow (Fig. 2), although reproductive endpoints were not affected. These results concur with those for NP-exposed medaka (Ishibashi et al., 2006). Similarly, at NP concentrations slightly higher than those of the present study (i.e., $25-51 \mu \mathrm{g} / \mathrm{L}$ ), Kang et al. (2003) observed increased hepatic VTG in medaka whereas reproductive endpoints (fecundity, fertility, and spermatogenesis) were only affected at considerably higher NP concentrations (101 and $184 \mu \mathrm{g} / \mathrm{L} \mathrm{NP}$ ).

\subsection{Histopathology}

Feminization of male rare minnows was observed and males manifested the testis-ova phenomenon (Table 1; Fig. 3). Some studies have showed that testis-ova were observed while fish were exposed to $\mathrm{EE}_{2}$ or NP (Lange et al., 2001; Seki et al., 2002; Kang et al., 2003). In addition, Kang et al. $(2002,2003)$ also reported histological lesions of the testis in $\mathrm{E}_{2}$ and NP-exposed medaka that included replacement of normal tissue by connective tissues and a lack of spermatogenesis coincident with decreased fecundity and fertility. Seki et al. (2002) showed that increased VTG and testes-ova endpoints in medaka were eight-fold more sensitive to $\mathrm{EE}_{2}$ compared with concentrations affecting reproduction.

A large amount of eosinophilic-staining material was observed in male liver and kidney of the $\mathrm{EE}_{2}$ and $20 \mu \mathrm{g} / \mathrm{L}$ NP-exposed group (Table 1; Fig. 4C, E, and F). Accumulation of esinophilic material was reported in flounder injected with $10 \mathrm{mg} / \mathrm{kg} \mathrm{E}_{2}$ (Zaroogian et al., 2001). Esinophilic material was most probably VTG (Herman and Kincaid, 1988), synthesized under the stimulation of estrogenic chemicals such as $\mathrm{EE}_{2}$, and accumulated in various tissues. In this study, hypertrophic and enlargement of nuclei of hepatocytes were observed. Schwaiger et al. (2000) reported hypertrophy of hepatocytes in common carp (Cyprinus carpio) which these authors attributed primarily to $\mathrm{EE}_{2}$ stimulation of VTG synthesis. Similarly, hypertrophy and degenerative and necrotic of the tubular epithelia were observed in estrogen treated carp (Schwaiger et al., 2000) and flounder (Zaroogian et al., 2001). These phenomena were observed in our pervious study (Zha et al., 2007). Therefore, significant increases of HSI and RSI (Fig. 1) could be consistent with VTG accumulation in these organs and hypertrophy of hepatocytes and tubular epithelia. 


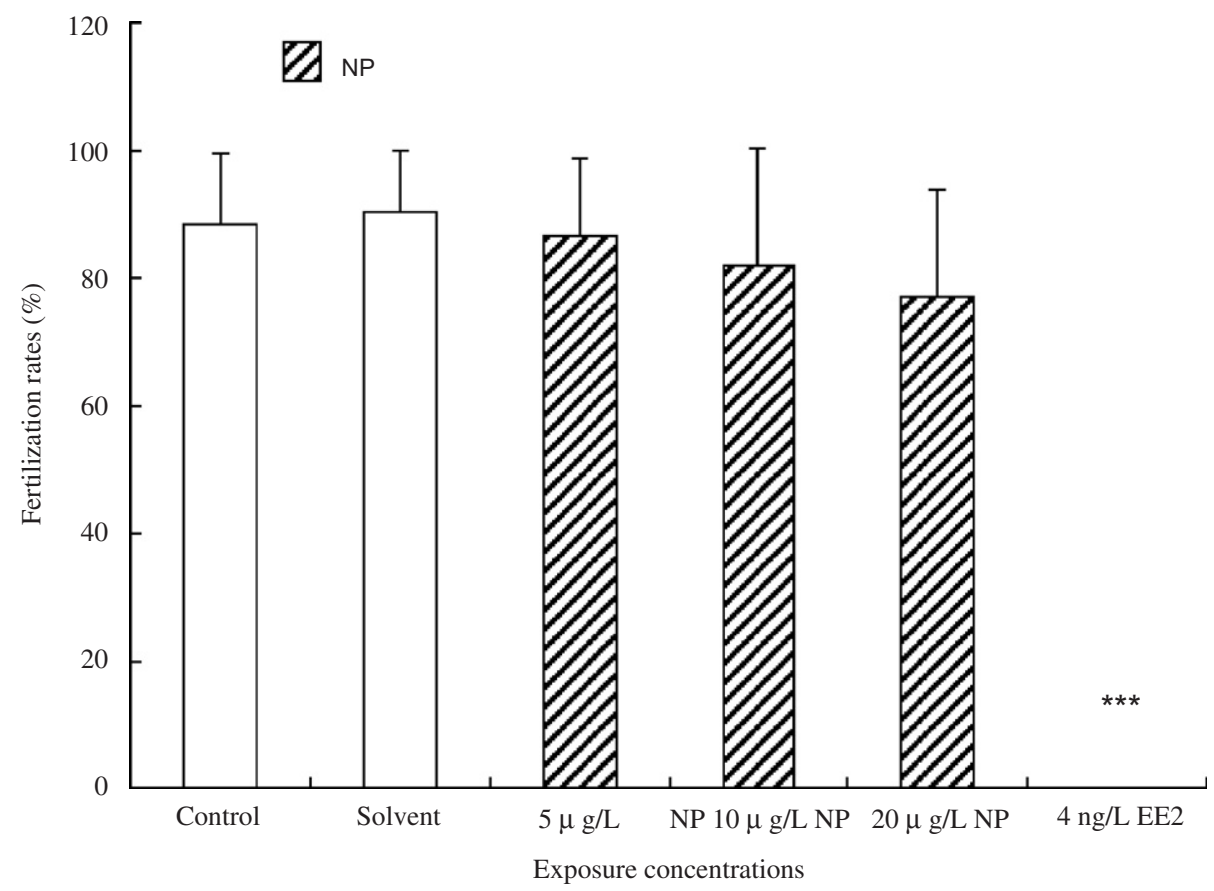

Fig. 7. Fertilization rates of eggs spawned by rare minnow during the 21 days reproductive assay. Asterisk $(* * *)$ indicates significant difference from the control group $(p<0.001)$.

Table 2

Hatching rates of embryos and growth and accumulative death rates of larvae at 15 days post-hatching from NP treatments and controls

\begin{tabular}{llllr}
\hline Concentration $(\mu \mathrm{g} / \mathrm{L})$ & Hatching rates $(\%)$ & Body length $(\mathrm{mm})$ & Body weight $(\mathrm{mg})$ & $\begin{array}{l}\text { Accumulative } \\
\text { death rates }(\%)\end{array}$ \\
\hline Control & $95.3 \pm 2.6$ & $9.5 \pm 0.1$ & $6.1 \pm 0.3$ & $11.2 \pm 3.6$ \\
Solvent & $93.6 \pm 5.9$ & $9.6 \pm 0.1$ & $6.2 \pm 0.3$ & \\
5 & $88.2 \pm 10.3$ & $9.1 \pm 0.4$ & $4.7 \pm 0.3$ & \\
10 & $80.7 \pm 12.5$ & $9.5 \pm 0.5$ & $5.0 \pm 0.6$ & $14.3 \pm 2.9$ \\
20 & $79.4 \pm 11.1$ & $8.8 \pm 0.7$ & $4.1 \pm 0.8$ & $12.4 \pm 7.8$ \\
\hline
\end{tabular}

\section{Conclusion}

The results of the present investigation indicate that a short-term reproductive bioassay is possible using the Chinese rare minnow as the test species. The bioassay succeeded in demonstrating that the synthetic estrogen $\mathrm{EE}_{2}$ was several orders of magnitude more potent than the industrial chemical NP. Among reproductive endpoints, fecundity, fertility, and the interval between spawnings were significantly affected by $4 \mathrm{ng} / \mathrm{L} \mathrm{EE} \mathrm{E}_{2}$. These effects coincided with male feminization, ova-testis, increased plasma VTG in both males and females as well as the accumulation of eosinophilic material in kidneys and liver. Histopathologic evaluation revealed severe kidney lesions in both $\mathrm{EE}_{2}$ and NP-exposed fish. Based on the limited data, the rare minnow was more sensitive to $\mathrm{EE}_{2}$ than medaka, but comparable to zebrafish in terms of sensitivity.

\section{Acknowledgments}

We gratefully acknowledge the support of National Basic Research Program of China (2007CB407304) and the
National Natural Science Foundation of China (20677075, 50538090).

\section{References}

Ahel, M., Giger, W., Koch, M., 1994. Behaviour of alkylphenol polyethoxylate surfactants in the aquatic environment: I. Occurrence and transformation in sewage treatment. Water Res. 28, 1131-1142.

Ankley, G.T., Jensen, K.M., Kahl, M.D., Korte, J.J., Makynen, E.A., 2001. Description and evaluation of a short-term reproduction test with the fathead minnow (Pimephales promelas). Environ. Toxicol. Chem. 20, 1276-1290.

Blackburn, M.A., Waldock, M.J., 1995. Concentrations of alkylphenols in rivers and estuaries in England and Wales. Water Res. 29, 1623-1629.

Gray, M.A., Metcalfe, C.D., 1997. Induction of testis-ova in Japanese medaka (Oryzias latipes) exposed to $p$-nonylphenol. Environ. Toxicol. Chem. 16, 1082-1086.

Groonen, S., Denslow, N., Manning, S., Barnes, S., Barnes, D., Brouwer, M., 1999. Serum vitellogenin levels and reproductive impairment of male Japanese medaka (Oryzias latipes) exposed to 4-tert-octylphenol. Environ. Health Perspect. 107, 385-390.

Hahlbeck, E., Katsiadaki, I., Mayer, I., Adolfsson-Erici, M., James, J., Bengtsson, B., 2004. The juvenile three-spined stickleback (Gasterosteus aculeatus $\mathrm{L}$.) as a model organism for endocrine disruption: II. 
Kidney hypertrophy, vitellogenin and spiggin induction. Aquat. Toxicol. 70, 311-326.

Harries, J.E., Runnalls, T., Hill, E., Harris, C.A., Maddix, S., Sumpter, J.P., Tyler, C.R., 2000. Development of a reproductive performance test for endocrine disrupting chemicals using pair-breeding fathead minnows (Pimephales promelas). Environ. Sci. Technol. 34, 3003-3011.

Herman, R.L., Kincaid, H.L., 1988. Pathological effects of orally administered estradiol to rainbow trout. Aquaculture 72, 165-172.

Ishibashi, H., Hirano, M., Matsumura, N., Watanabe, N., Takao, Y., Arizono, K., 2006. Reproductive effects and bioconcentration of 4-nonylphenol in medaka fish (Oryzias latipes). Chemosphere 65, 1019-1026.

Jobling, S., Sheahan, D.A., Osborne, J.A., Matthiessen, P., Sumpter, J.P., 1996. Inhibition of testicular growth in rainbow trout (Oncorhynchus mykiss) exposed to estrogenic alkylphenolic chemicals. Environ. Toxicol. Chem. 15, 194-202.

Kang, I.J., Yokota, H., Oshima, Y., Tsuruda, Y., Yamaguchi, T., Maeda, M., Imada, N., Tadokoro, H., Honjo, T., 2002. Effect of 17ß-estradiol on the reproduction of Japanese medaka (Oryzias latipes). Chemosphere 47, 71-80.

Kang, I.J., Yokota, H., Oshima, Y., Tsuruda, Y., Hano, T., Maeda, M., Imada, N., Tadokoro, H., Honjo, T., 2003. Effects of 4-nonylphenol on reproduction of Japanese medaka, Oryzias latipes. Environ. Toxicol. Chem. 22, 2438-2445.

Kolpin, D.W., Furlong, E.T., Meyer, M.T., Thurman, E.M., Zaugg, S.D., Barber, L.B., Buxton, H.T., 2002. Pharmaceuticals, hormones, and other organic wastewater contaminants in US streams, 1999-2000: a national reconnaissance. Environ. Sci. Technol. 36, 1202-1211.

Komori, K., Tanaka, H., Okayasu, Y., Yasojima, M., Sato, C., 2004. Analysis and occurrence of estrogen in wastewater in Japan. Water Sci. Technol. 50, 93-100.

Kramer, V.J., Miles-Richardson, S., Pierens, S.L., Giesy, J.P., 1998 Reproductive impairment and induction of alkaline-labile phosphate, a biomarker of estrogen exposure, in fathead minnows (Pimephales promelas) exposed to waterborne 17ß-estradiol. Aquat. Toxicol. 40, 335-360.

Lange, R., Hutchinson, T.H., Croudace, C.P., Siegmund, F., Schweinfurth, H., Hampe, P., Panter, G.H., Sumpter, J.P., 2001. Effects of the synthetic estrogen $17 \alpha$-ethinylestradiol on the life-cycle of the fathead minnow (Pimephales promelas). Environ. Toxicol. Chem. 20 (6), $1216-1227$.

Liney, K.E., Jobling, S., Shears, J.A., Simpson, P., Tyler, C.R., 2005. Assessing the sensitivity of different life stages for sexual disruption in roach (Rutilus rutilus) exposed to effluents from wastewater treatment works. Environ. Health Perspect. 113, 1299-1307.

Meier, S., Andersen, T.E., Norberg, B., Thorsen, A., Taranger, G.L., Kjesbu, O.S., Dale, R., Morton, H.C., Klungsøyr, J., Svardal, A., 2007. Effects of alkylphenols on the reproductive system of Atlantic cod (Gadus morhua). Aquat. Toxicol. 81, 207-218.

Nakayama, K., Oshima, Y., Yamaguchi, T., Tsuruda, Y., Kang, I.J., Kobayashi, M., Imada, N., Honjo, T., 2004. Fertilization success and sexual behavior in male medaka, Oryzias latipes, exposed to tributyltin. Chemosphere 55, 1331-1337.

Nash, J.P., Kime, D.E., Van der Ven, L.T.M., Wester, P.W., Brion, F., Maack, G., Stahlschmidt-Allner, P., Tyler, C.R., 2004. Long-term exposure to environmental concentrations of the pharmaceutical ethynylestradiol causes reproductive failure in fish. Environ. Health Perspect. 112, 1725-1733.

Nichols, K.M., Miles-Richardson, S.R., Snyder, E.M., John, P., 1999. Effects of exposure to municipal wastewater in situ on the reproductive physiology of the fathead minnow (Pimephales promelas). Environ. Toxicol. Chem. 18, 2001-2012.

Oshima, Y., Kang, I.J., Kobayashi, M., Nakayama, K., Imada, N., Honjo, T., 2003. Suppression of sexual behavior in male Japanese medaka (Oryzias latipes) exposed to 17ß-estradiol. Chemosphere 50, 429-436.

Palace, V.P., Wautier, K.G., Evans, R.E., Blanchfield, P.J., Mills, K.H., Chalanchuk, S.M., Godard, D., Mcmaste, M.E., Tetreault, G.R., Peters, L.E., Vandenbyllaardt, L., Kidd, K.A., 2006. Biochemical and histopathological effects in pearl dace (Margariscus margarita) chronically exposed to a synthetic estrogen in a whole lake experiment. Environ. Toxicol. Chem. 25, 1114-1125.

Schwaiger, J., Spieser, O.H., Bauer, C., Ferling, H., Mallow, U., Kalbfus, W., Negele, R.D., 2000. Chronic toxicity of nonylphenol and ethinylestradiol: haematological and histopathological effects in juvenile Common carp (Cyprinus carpio). Aquat. Toxicol. 51, 69-78.

Seki, M., Yokota, H., Matsubara, H., Tsuruda, Y., Maeda, M., Tadokoro, H., Kobayashi, K., 2002. Effect of ethinylestradiol on the reproduction and induction of vitellogenin and testis-ova in medaka (Oryzias latipes). Environ. Toxicol. Chem. 21, 1692-1698.

Solé, M., Raldua, D., Piferrer, F., Barceló, D., Portea, C., 2003. Feminization of wild carp, Cyprinus carpio, in a polluted environment: plasma steroid hormones, gonadal morphology and xenobiotic metabolizing system. Comp. Biochem. Physiol. C 136, 145-156.

Ternes, T.A., Stumpf, M., Mueller, J., Harberer, K., Wilken, R.D., Servos, M., 1999. Behavior and occurrence of estrogen in municipal sewage treatment plants-investigations in Germany, Canada and Brazil. Sci. Total Environ. 225, 81-90.

Thomas, K.V., Balaam, J., Hurst, M.R., Thain, J.E., 2004. Identification of in vitro estrogen and androgen receptor agonists in North Sea offshore produced water discharges. Environ. Toxicol. Chem. 23, 1156-1163.

Thorpe, K.L., Cummings, R.I., Hutchinson, T.H., Scholze, M., Brighty, G., Sumpter, J.P., 2003. Relative potencies and combination effects of steroidal estrogens in fish. Environ. Sci. Technol. 37, 1142-1149.

Tolls, J., Kloepper-Sams, P., Sijm, D., 1994. Surfactant bioconcentrations - a critical review. Chemosphere 29, 693-717.

Tsuda, T., Takino, A., Muraki, K., Harada, H., Kojima, M., 2001. Evaluation of 4-nonylphenols and 4-tert-octylphenol contamination of fish in rivers by laboratory accumulation and excretion experiments. Water Res. 35, 1786-1792.

Van den Belt, K., Verheyen, R., Witters, H., 2001. Reproductive effects of ethynylestradiol and 4-t-octylphenol on the zebrafish (Danio rerio). Arch. Environ. Contam. Toxicol. 41, 458-467.

Van den Belt, K., Wester, P.W., van der Ven, L.T.M., Verheyen, R., Witters, H., 2002. Effects of ethynylestradiol on the reproductive physiology in zebrafish (Danio rerio): time dependency and reversibility. Environ. Toxicol. Chem. 21, 767-775.

Van den Belt, K., Verheyen, R., Witters, H., 2003. Effects of $17 \alpha$-ethynylestradiol in a partial life-cycle test with zebrafish (Danio rerio): effects on growth, gonads and female reproductive success. Sci. Total Environ. 309, 127-137.

Van den Belt, K., Berckmans, P., Vangenechten, C., Verheyen, R., Witters, H., 2004. Comparative study on the in vitro/in vivo estrogenic potencies of $17 \beta$-estradiol, estrone, $17 \alpha$-ethynylestradiol and nonylphenol. Aquat. Toxicol. 66, 183-195.

Wang, J., 1992. Reproductive biology of Gobiocypris rarus. Acta Hydrobiol. Sinica 16, 165-174.

Yokota, H., Seki, M., Maeda, M., Oshima, Y., Tadokoro, H., Honjo, T., Kobayashi, K., 2001. Life-cycle toxicity of 4-nonylphenol to medaka (Oryzias latipes). Environ. Toxicol. Chem. 20, 2552-2560.

Zaroogian, G., Gardner, G., Borsay Horowitz, D., Gutjahr-Gobell, R., Haebler, R., Mills, L., 2001. Effect of 17ß-estradiol, $o, p^{\prime}$-DDT, octylphenol and $p, p^{\prime}$-DDE on gonadal development and liver and kidney pathology in juvenile male summer flounder (Paralochthys dentatus). Aquat. Toxicol. 54, 101-112.

Zha, J., Wang, Z., Wang, N., Ingersoll, C., 2007. Histological alternation and vitellogenin induction in adult rare minnow (Gobiocypris rarus) after exposure to ethynylestradiol and nonylphenol. Chemosphere 66, 488-495.

Zhou, Y., Cheng, S., Hu, W., Sun, M., 1995. A new toxicity test organism-Gobiocypris rarus. Zool. Res. 16, 59-63.

Zhou, Y., Ma, M., Wang, Z., 2005. Determination of nonylphenols in water by pre-column derivatization and gas chromatography coupled with mass spectrometry. Chinese J. Anal. Chem. 33, 1109-1112.

Zhou, Y., Wang, Z., Jia, N., 2007. Formation of multiple trimethylsilyl derivatives in the derivatization of $17 \alpha$-ethinylestradiol with BSTFA or MSTFA followed by gas chromatography-mass spectrometry determination. J Environ. Sci. 19, 879-884. 